\title{
DIABETIC JEOPARDIZE OF ACUTE MYOCARDIAL INFARCTION CHEST PAIN
}

\author{
Gul Zaman Khan Niazi', Nisar Ahmed ${ }^{1}$, Arslan Masood², Ammar Akhtar ${ }^{1}$, Muhammad Sohail Saleemi ${ }^{1}$, ljaz \\ Ahmad $^{1}$
}

1 Chaudhry Pervaiz Elahi Institute of Cardiology, Multan, Pakistan

2 Allama lqbal Medical College, Lahore, Pakistan

Address for Correspondence:

Dr. Gul Zaman Khan Niazi

Chaudhry Pervaiz Elahi Institute of

Cardiology, Multan, Pakistan

Email: med_student62@yahoo.com

\section{Contribution}

GZKN conceived the idea and designed the study. Data collection and manuscript writing was done by GZKN, NA, AM, AA, MSS, and IA. All the authors contributed equally to the submitted manuscript.

All authors declare no conflict of interest.

This article may be cited as: Niazi GZK, Ahmed N, Masood A, Akhtar A, Saleemi MS, Ahmad I. Diabetic Jeopardize of Acute Myocardial Infarction Chest Pain. Pak Heart $\mathrm{J}$ 2020;53(04):349-353.

https://doi.org/10.47144/phj.v53i $\underline{4.1983}$

\section{ABSTRACT}

Objective: Diabetic neuropathy may mask the typical ischemic chest pain and diabetics may carry longer presentation times in cases of acute STEMI. Diabetics may complain of chest pain less frequently, while atypical clinical presentations of STEMI could be more common compared to non-diabetics. Aim of this study was to assess the potential impact of diabetes on STEMI related chest pain, its severity, characteristics and nonspecific clinical features.

Methodology: The descriptive, cross-sectional study included 254 patients with first episode of STEMI. Data was acquired regarding feeling of chest pain, its severity, different characters, sites of radiation, and occurrence of associated clinical features. These variables were compared among diabetic and non-diabetic groups by Pearson's Chi-square test.

Results: Diabetics were more likely 'not to feel' any STEMI related chest pain compared to non-diabetics $(22.2 \%$ vs. $2.4 \% p<0.001)$, severe chest pain was a less frequent complaint in diabetics compared to non-diabetics $(21.1 \%$ vs. $89 \% \quad p<0.001)$. The characters of "chest tightness", "strangulating pain" and "squeezing chest pain" were less frequent in diabetics ( $45.6 \%$ vs. $68.3 \% \mathrm{p}<0.001,8.9 \%$ vs. $56.7 \% \mathrm{p}<0.001$ and $1.1 \%$ vs. $18.3 \% p<0.001$ respectively). Syncope and shortness of breath were observed more frequently in diabetics (37.8\% vs. $20.7 \% p=0.003$ and $23.3 \%$ vs. $17.1 \% p=0.001$ respectively).

Conclusion: Diabetics can frequently present without pain or with less severe chest pain and infrequent typical characters compared to nondiabetics and may have atypical symptoms like syncope and shortness of breath more commonly than non-diabetics.

Keywords: Diabetes mellitus, ST-Elevation Myocardial Infarction, Chest pain, Ischemic heart disease 


\section{INTRODUCTION}

ST-segment Elevation Myocardial infarction (STEMI) is among the leading causes of morbidity and mortality worldwide with more than nine million people suffering from ischemic heart disease (IHD). ${ }^{1,2}$ Diabetes mellitus (DM) is one of the major modifiable risk factors for IHD and is also considered as an equivalent to coronary artery disease (CAD). ${ }^{3}$ In addition to its major role in the development of atherosclerosis and CAD, it may frequently cause peripheral and autonomic neuropathy, vasculopathy and diabetic cardiomyopathy. ${ }^{4}$

Diabetes has been linked to a higher risk for CAD and almost twice short- and long-term mortality after STEMI compared to non-diabetics. ${ }^{5}$ Around $20 \%$ diabetics have an abnormal cardiovascular autonomic function. ${ }^{6}$ This could lead to the atypical presentations of myocardial ischemia and acute STEMI. ${ }^{7}$ Associated peripheral neuropathy may mask the typical ischemic chest pain and diabetics have been shown to carry longer presentation times compared to non-diabetics in cases of acute STEMI. ${ }^{5}$ Diabetics may complain of chest pain less frequently, while atypical clinical presentations of STEMI could be more common compared to nondiabetics. ${ }^{8,9}$

In cases of acute STEMI, myocardial salvage and mortality reduction depends largely on earliest reperfusion strategies. ${ }^{10}$ About 18 to $40 \%$ patients present later than 12 hours of STEMI onset in European and North American well-developed systems of care. ${ }^{11,12}$ Even more patients present late in the healthcare systems of developing countries. ${ }^{13}$ In addition to the circumstantial, logistic, social and educational factors contributing to such delays, diabetes may contribute by masking the typical chest pain or discomfort so that a substantial proportion of persons suffering from acute STEMI may not attribute their symptoms to it at an early stage. The study was conducted to assess the potential impact of diabetes on STEMI related chest pain, its severity, characteristics and non-specific clinical features. Findings of the study could provide insight on how diabetes can mislead diabetic STEMI patients in recognizing their initial symptoms as well as pose difficulties to the first contact healthcare workers in diagnosing STEMI in its earliest phase while the electrocardiographic and biomarker evidences are still awaited. Important inferences drawn from the study could be incorporated into general population-based educational and social awareness programs in addition to further enlightening the first contact healthcare providers to consider the potential impact of diabetes while assessing possible STEMI patients.

\section{METHODOLOGY}

The descriptive, cross-sectional study was conducted in patients admitted in Emergency department of Cardiology unit of Chaudhary Pervaiz Elahi Institute of Cardiology, Multan for a period of six months. Total of 254 consecutive patients with first episode of STEMI were included in the study after approval from Ethical and Research Review Committee of the institute and informed consent from the patients.

Demographic parameters and CAD risk factor profiles were recorded. Questions were asked about the chest pain and its severity was graded via verbal rating scale of pain with score 1-4 as mild pain, 5-7 as moderate pain, $8-10$ as severe pain. Specific characters of chest pain (pressure over precordium, strangulating pain, squeezing pain and burning over precordium) were also inquired. Patients were also asked about the radiation of chest pain or discomfort to left arm, both arms, neck, lower jaw, interscapular region, or epigastrium. Patients were then assessed for occurrence of associated clinical features to chest discomfort including episodes of vomiting, profuse sweating (all over the body, drenching clothes and irritating for the patient), syncope, shortness of breath, fits, and indigestion symptoms. Patients were labelled as diabetics if already on hypoglycemic drugs, $\mathrm{HbA} 1 \mathrm{C}>7.0 \%$ or fasting blood glucose $>120 \mathrm{mg} / \mathrm{dL}$.

All data was analyzed by computer software SPSS version 20. Demographics and STEMI types were assessed and stratified among diabetic and nondiabetic groups. Chest pain severities, characters, radiations and associated clinical features were compared among diabetic and non-diabetic groups by Pearson's Chi-square test. 


\section{RESULTS}

The study included 90(35.4\%) diabetics and 164 $(64.6 \%)$ non-diabetics. Demographic features of study population are detailed in Table 1.

Table 1: Distribution of demographic features, other CAD risk factors and STEMI types among diabetic and non-diabetics

\begin{tabular}{|l|c|c|c|}
\hline & Total & DM & Non-DM \\
\hline N & 254 & 90 & 164 \\
\hline Age(years) & $54.8 \pm$ & $58.9 \pm$ & $52.7 \pm$ \\
\hline Males & 10.9 & 9.3 & 11.5 \\
& 183 & 50 & 131 \\
\hline Females & $(72 \%)$ & $(55.6 \%)$ & $(79.9 \%)$ \\
\hline Dyslipidemia & 71 & 40 & 33 \\
& $(28 \%)$ & $(44.4 \%)$ & $(20.1 \%)$ \\
\hline Hypertension & 101 & 71 & 30 \\
\hline Smoking & $(39.8 \%)$ & $(78.9 \%)$ & $(18.3 \%)$ \\
\hline FHx & 78 & 31 & 47 \\
& $(30.7 \%)$ & $(34.4 \%)$ & $(28.7 \%)$ \\
\hline Anterior STEMI & 99 & 20 & 79 \\
& $(39 \%)$ & $(22.2 \%)$ & $(48.2 \%)$ \\
\hline Inferior STEMI & 82 & 32 & 50 \\
\hline Inferolateral STEMI & $(32.3)$ & $(35.6 \%)$ & $(30.5 \%)$ \\
\hline DM: diabetics, & $(2.2 \%)$ & 54 & 109 \\
\hline
\end{tabular}

DM: diabetics, FHx: Family history of coronary artery diseases, STEMI: ST elevation myocardial infarciton

Anterior STEMI was the most frequent type (64.2\%) followed by inferior STEMI $(30.7 \%)$ and inferolateral STEMI (2.8\%). Diabetics were more likely 'not to feel' any STEMI related chest pain compared to nondiabetics (22.2\% vs. $2.4 \%)$, a mild degree of chest pain was more frequent in diabetic group compared to non-diabetics ( $15.6 \%$ vs. $0 \%$ ) while severe pain was a less frequent complaint in diabetics compared to non-diabetics $(21.1 \%$ vs. $89 \%)(p<0.001)$ (Figure $1)$.
Regarding the character of chest pain, "chest tightness" was the most frequent character $(60.2 \%)$. The characters of "chest tightness", "strangulating pain" and "squeezing chest pain" were less frequent in diabetics compared to non-diabetics $(45.6 \%$ vs. $68.3 \% \mathrm{p}<0.001,8.9 \%$ vs. $56.7 \% \mathrm{p}<0.001$ and $1.1 \%$ vs. $18.3 \% \quad p<0.001$ respectively) (Table 2). Frequencies of "pressure" and "burning sensation" over precordium were not significantly different among diabetics and non-diabetics $(34.4 \%$ vs. $45.1 \% \quad \mathrm{p}=0.127$ and $7.8 \%$ vs. $3 \% \quad \mathrm{p}=0.089$ respectively) (Table 2 ).

Figure 1: Distribution of chest pain severity among diabetics and non-diabetics

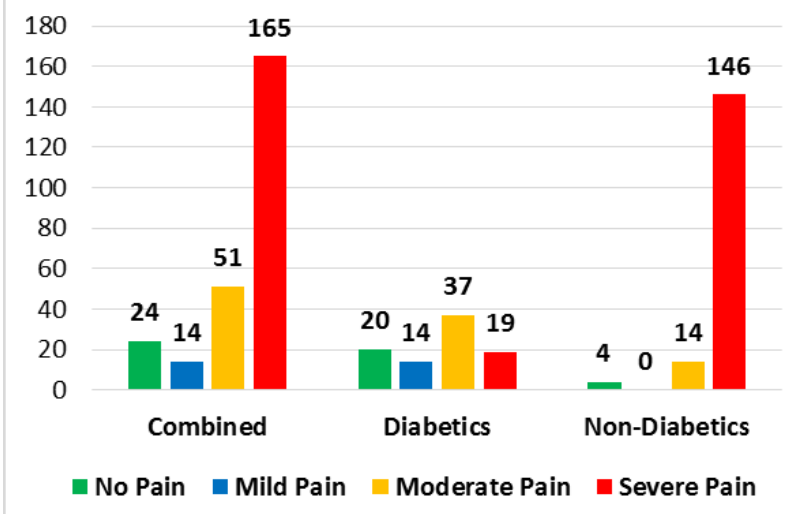

Left arm was the most frequent site of pain radiation (46.6\%), followed by interscapular radiation (33\%). Radiations to left arm, interscapular region and lower jaw were less frequent in diabetics compared to non-diabetics $(36.7 \%$ vs. $51.8 \% p=0.02,22.2 \%$ vs. $39 \% p<0.001$ and $11.1 \%$ vs. $29.3 \% p=0.001$ respectively) (Table 2 ).

Regarding associated clinical features other that chest pain, vomiting and sweating occurred less frequently in diabetics compared to non-diabetics $(40 \%$ vs. $51.2 \% \quad p=0.041$ and $15.6 \%$ vs. $44.5 \%$ $\mathrm{p}<0.001$ respectively), while syncope and shortness of breath were more frequent in diabetics compared to non-diabetics (37.8\% vs. $20.7 \% \quad \mathrm{p}=0.003$ and $23.3 \%$ vs. $17.1 \% \mathrm{p}=0.001$ respectively) (Table 2 ).

Table 2: Distribution of chest discomfort patterns, pain radiation patterns, and associated features among diabetics and non-diabetics

\begin{tabular}{|l|c|c|c|c|}
\hline & Total & Diabetics & Non-diabetics & p-value \\
\hline N & 254 & 90 & 164 & - \\
\hline Chest discomfort patterns & & & & \\
\hline Chest tightness & $153(60.2 \%)$ & $41(45.6 \%)$ & $112(68.3 \%)$ & $<0.001$ \\
\hline Pressure over precordium & $105(41.3 \%)$ & $31(34.4 \%)$ & $74(45.1 \%)$ & 0.127 \\
\hline Strangulating pain & $101(39.7 \%)$ & $8(8.9 \%)$ & $93(56.7 \%)$ & $<0.001$ \\
\hline
\end{tabular}




\begin{tabular}{|l|c|c|c|c|}
\hline Squeezing chest pain & $31(12.2 \%)$ & $1(1.1 \%)$ & $30(18.3 \%)$ & $<0.001$ \\
\hline \begin{tabular}{l} 
Burning sensation over precordium \\
\hline Pain radiation patterns
\end{tabular} & $12(4.7 \%)$ & $7(7.8 \%)$ & $5(3 \%)$ & 0.089 \\
\hline Left arm radiation & $118(46.4 \%)$ & $33(36.7 \%)$ & $85(51.8 \%)$ & 0.02 \\
\hline Radiation to interscapular region & $84(33 \%)$ & $20(22.2 \%)$ & $64(39 \%)$ & $<0.001$ \\
\hline Radiation to epigastrium & $78(30.7 \%)$ & $31(34.4 \%)$ & $47(28.7 \%)$ & 0.495 \\
\hline Radiation to lower jaw & $58(22.8 \%)$ & $10(11.1 \%)$ & $48(29.3 \%)$ & 0.001 \\
\hline Bilateral arm radiation & $30(11.8 \%)$ & $6(6.7 \%)$ & $24(14.6 \%)$ & 0.06 \\
\hline Radiation to neck & $14(5.5 \%)$ & $7(7.8 \%)$ & $7(4.3 \%)$ & 0.241 \\
\hline Associated features & & & & \\
\hline Episode of vomiting & $120(47.2 \%)$ & $36(40 \%)$ & $84(51.2 \%)$ & 0.041 \\
\hline Profuse sweating & $87(34.3 \%)$ & $14(15.6 \%)$ & $73(44.5 \%)$ & $<0.001$ \\
\hline Syncope & $68(26.8 \%)$ & $34(37.8 \%)$ & $34(20.7 \%)$ & 0.003 \\
\hline Shortness of breath & $49(19.3 \%)$ & $21(23.3 \%)$ & $28(17.1 \%)$ & 0.001 \\
\hline Fits & $25(9.8 \%)$ & $13(1.9 \%)$ & $12(19.7 \%)$ & 0.068 \\
\hline Feeling of indigestion & $22(8.7 \%)$ & $8(8.9 \%)$ & $14(8.5 \%)$ & 0.924 \\
\hline
\end{tabular}

\section{DISCUSSION}

The incidence of myocardial infarction (MI) is highest in South-Asia. ${ }^{14}$ Around $90 \%$ of these cases have modifiable risk factors like diabetes, hypertension, smoking, etc. ${ }^{2}$ Diabetic patients have a higher risk for $\mathrm{Ml}$ and twice the short as well as long-term mortality after $\mathrm{Ml}$ as compared to non-diabetic patients. ${ }^{15-17}$ Chest pain is the commonest symptom experienced by patients but it can differ in nature and severity among diabetics and non-diabetics. ${ }^{18}$ Atypical presentation and presentation without chest pain is also reported in diabetics. ${ }^{9}$

Gradiser et al reported a majority of diabetic patients presenting with severe chest pain, however, 51.7\% of diabetics had a mild or no pain at all. ${ }^{7}$ Canto et al also reported a large number of diabetic patients with lack of chest pain. ${ }^{19}$ In our study, $22.2 \%$ of diabetic patients with acute STEMI had no chest pain at all and only $21.1 \%$ diabetics complained of severe chest pain, the majority of diabetics complained of moderate chest pain. These results are comparable to studies by Gradiser and Canto. Kennel et al and Rutter et al also showed the incidence of silent ischemia being more among diabetics as compared to non-diabetics. ${ }^{3,20}$

Diabetics may experience the pain of acute STEMI in the epigastric region more frequently compared to non-diabetics. ${ }^{5}$ Similar observation was reported by Tbibiazeret al. ${ }^{9}$ In our study, $34.4 \%$ of diabetic patients had epigastric discomfort, however, it was not statistically different from non-diabetics $(34.4 \%$ vs. $28.7 \% p=0.495)$. Zellweger et al reported $11 \%$ diabetic patients with shortness of breath as the symptom of CAD. ${ }^{21}$ Our study showed that $23.3 \%$ diabetic patients complaint of shortness of breath which could be due to late presentation in diabetics leading to poor left ventricular function. In our study, shortness of breath and syncope were in fact more commonly associated with diabetics compared to the other group, thus emphasizing the importance of recognizing atypical symptoms in non-diabetics. The findings of this study may contribute to the understanding that diabetic patients may have less severe symptoms and atypical presentations emphasizing the need for more care and vigilance during their evaluation for possible STEMI.

\section{Limitations}

The major limitation of this study is being a singlecenter cross-sectional survey conducted with limited sample size. Additionally, duration and control of diabetes and their potential impacts on chest pain severity and patterns were not accounted for. Future research on the subject may be conducted with multicenter larger study populations incorporating potential impacts of missing factors from this study.

\section{CONCLUSION}

Diabetics can frequently present without pain or with less severe chest pain and infrequent typical characters compared to non-diabetics and may have atypical symptoms like syncope and shortness of breath more commonly than non-diabetics. 


\section{REFERENCES}

1. Vogel B, Claessen BE, Arnold SV, Chan D, Cohen DJ, Giannitsis E, et al. ST-segment elevation myocardial infarction. Nat Rev Dis Primers. 2019;5(1):39.

2. Global Health Estimates 2016: Deaths by Cause, Age, Sex, by Country and by Region, 2000- 2016. Geneva, Switzerland: World Health Organization; 2018.

3. Kannel WB, McGee DL. Diabetes and cardiovascular disease: the Framingham study. JAMA. 1979;241:2035-8

4. Luscher TF, Creager MA, Beckman JA, Cosentino F. Diabetes and vascular disease: Pathophysiology, clinical consequences, and medical therapy: Part II. Circulation. 2003;108:1655-61.

5. Ahmed S, Khan A, Ali SI, Jawaid H, Islam M, Saiyed $\mathrm{H}$, et al. Differences in symptoms and presentation delay times in myocardial infarction patients with and without diabetes: A crosssectional study in Pakistan. Indian Heart J. 2018;70(2): 241-5.

6. Creager MA, Luscher TF, Cosentino F, Beckman JA. Diabetes and vascular disease: Pathophysiology, clinical consequences, and medical therapy: Part I. Circulation. 2003;108:1527-32.

7. Gradiser M, Dilber D, Cmrecnjak J, Ostricki B, Bilic-Curcic I. Comparison of the hospital arrival time and differences in pain quality between diabetic and non-diabetic STEMI patients. Int $\mathrm{J}$ Environ Res Public health. 2015;12(2):1387-96.

8. Culic V, Eterovic D, Miric D, Silic N. Symptom presentation of acute myocardial infarction: influence of sex, age, and risk factors. Am Heart J. 2002;144(6):1012-7.

9. Tbibiazar R, Edelman SV. Silent ischemia in people with diabetes: A condition that must be heard. Clin Diabetes. 2003;21:5-9

10. Simoons ML, Serruys PW, Van den Brand M, Res J, Verheugt FW, Kerhauss KH, et al. Early thrombolysis in acute myocardial infarction: limitation of infarct size and improved survival. J Am Coll Cardiol. 1986;7:717-28.

11. Cohen M, Gensini GF, Maritz F,Gurfinkel EP, Huber K, Timerman A, et al. Prospective evaluation of clinical outcomes after acute ST elevation myocardial infarction in patients who are ineligible for reperfusion therapy: preliminary results from the TETAMI registry and randomized trial. Circulation. 2003;108:14-21.

12. Sheifer SE, Rathore SS, Gersh BJ, Weinfurt KP, Oetgen WJ, Breall JA, et al. Time to presentation with acute myocardial infarction in the elderly: Associations with race, sex, and socioeconomic characteristics. Circulation 2000;102:1651-6.

13. Mohanan PP, Mathew $R$, Harikrishnan $S$, Krishnan MN, Zachariah G, Joseph J, et al. Presentation, management, and outcomes of 25748 acute coronary syndrome admissions in Kerala, India: Results from the Kerala ACS Registry. Eur Heart J 2012;34:121-9.

14. Joshi $P$, Islam $S, P a i s ~ P$. Risk factors for early myocardial infarction in South Asians compared with individuals in other countries. JAMA. 2007;297:286-94.

15. Rydén L, Standl E, Bartnik M. Guidelines on diabetes, pre-diabetes, and cardiovascular diseases: executive summary: The Task Force on Diabetes and Cardiovascular Diseases of the European Society of Cardiology (ESC) and of the European Association for the Study of Diabetes (EASD). Eur Heart J. 2007;28:88-136.

16. Yusuf S., Hawken S., Ônpuu S. Effect of potentially modifiable risk factors associated with myocardial infarction in 52 countries (the INTERHEART study): case-control study. Lancet. 2004;364:937-52.

17. Haffner SM, Lehto S, Rönnemaa T, Pyorala K, Laakso M. Mortality from coronary heart disease in subjects with type 2 diabetes and in no diabetic subjects with and without prior myocardial infarction. $\mathrm{N}$ Engl $\mathrm{J}$ Med. 1998;339:229-34.

18. Fors A, Dudas K, Ekman I. Life is lived forwards and understood backwards-experiences of being affected by acute coronary syndrome: a narrative analysis. Int J Nurs Stud. 2014;51:4307.

19. Canto JG, Shlipak MG, Rogers WJ. Prevalence, clinical characteristics, and mortality among patients with myocardial infarction presenting without chest pain. JAMA. 2000;283:3223-9.

20. Rutter MK, McComb JM, Brady S, Marshall SM. Detection of silent myocardial ischemia and microalbuminuria in asymptomatic subjects with non-insulin dependent diabetes mellitus. Am J Cardiol. 1999;83(1):27-31 .

21. Zellweger MJ, Hachamovitch R, Kang X, Hayes SW, Friedman JD, Germano G, et al. Prognostic relevance of symptoms versus objective evidence of coronary artery disease in diabetic patients. Eur. Heart J. 2004;25:543-50. 